\title{
Size at birth and growth in the first year of life of babies who are overweight and underweight at birth
}

\author{
By D. P. Davies, Department of Child Health, University of Leicester
}

\section{Introduction}

Weight gain and, to a lesser extent, gain in length are widely used means of assessing health and nutritional status of babies. For this purpose the use of centile charts are encouraged in baby clinics both in hospital and community. However, interpreting curves of weight gain constructed from serial recordings of weight is not always an easy matter. In the early months after birth the baby, after escaping the strong maternal influence on its intra-uterine growth rate, begins to seek its own genetically determined growth trajectory. This process accounts for great variations in weight gain and length growth during early infancy (Fomon, 1974) which are seen as upward and downward centile crossings when charted against standard growth curves. Shifting growth appears to be seen particularly in babies who are overweight (heavy-for-dates) and underweight (light-for-dates) at birth. (In this paper HFD and LFD babies are defined as those with birth weights above and below the 95th and $5^{\text {th }}$ centiles respectively using the standards of Tanner \& Thompson (1970) with allowances for maternal height, parity and infant sex. Babies of diabetic mothers are not included.) I would like to make some comparisons and contrasts in the physical dimensions at birth of these two categories of baby and in their patterns of weight gain and growth in length over the first year of postnatal life. For completeness and in view of the fact that weight is such a composite measurement, head circumference and skinfold thickness growth are also described.

In recent years a major contribution to our knowledge about the growth of babies at the extremes of size at birth has come from Dr Margaret Ounsted and her colleagues in Oxford (see Ounsted \& Ounsted, 1973, for general review). However, many of these studies are cross sectional, often with only two measurements made on individual children at different ages, and they are therefore unsuited to investigate the various growth patterns which might occur over the first year. In this study I have adopted the alternative approach of studying longitudinal growth patterns. The babies concerned are a personal series whose growth measurements have been prospectively collected over the last 5 years.

\section{Size at Birth}

HFD babies. As a group these are much longer than average (Fig. I). Their mean head circumference is also bigger, although not to quite the same extent as their greater length. Using the Ponderal Index $\left(\frac{\text { weight }(\mathrm{g})}{\text { length }(\mathrm{cm})} 3 \times 100\right)$ (Rohrer, 192 I ; 


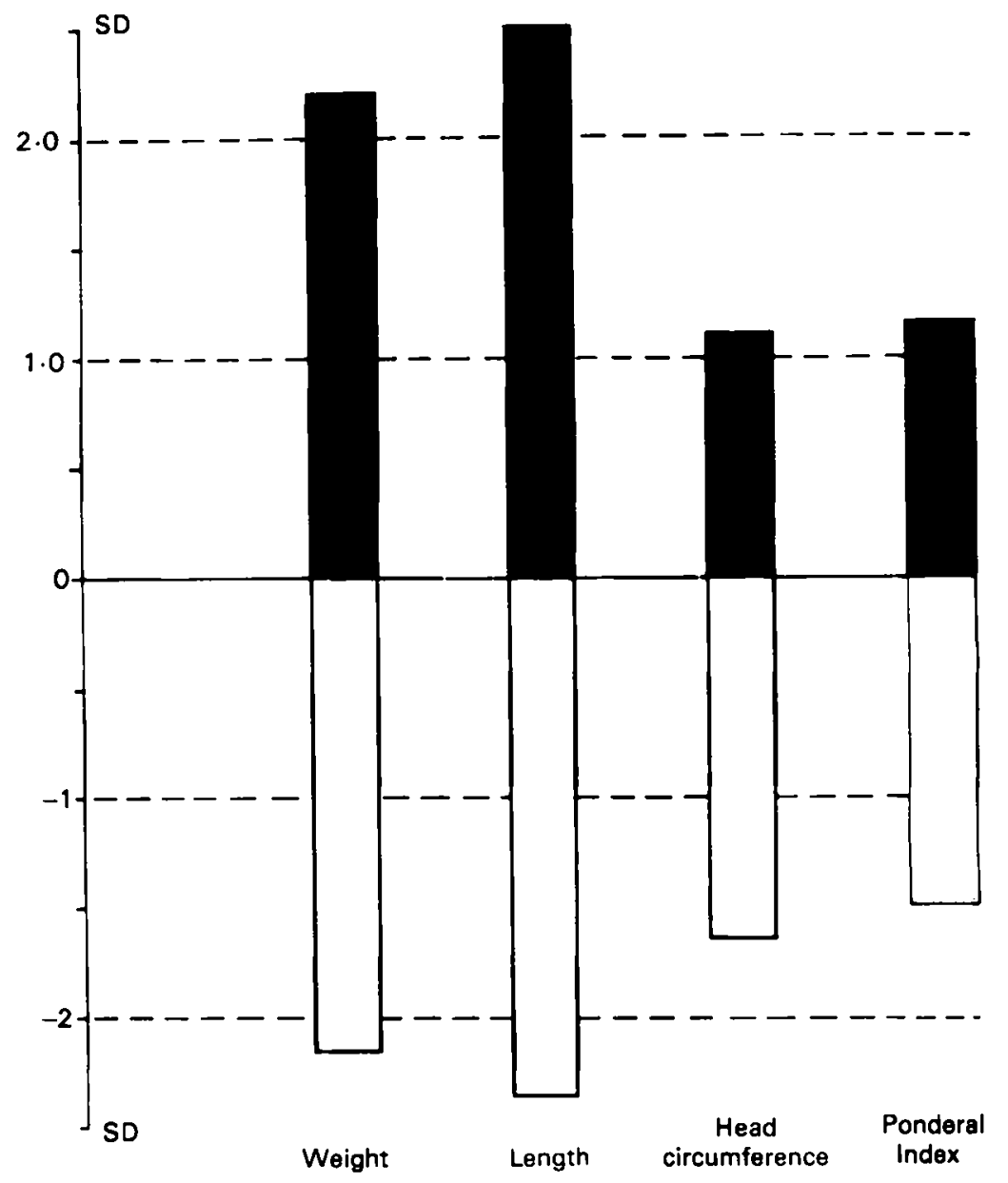

Fig. I. Deviation from values for normal babies of mean weight, length, head circumference and Ponderal Index in $(\square)$, heavy-for-dates $\left(n 3^{8}\right)$ and $(\square)$, light-for-dates $(n+7)$ babies. Expressed as fractions of the respective standard deviations.

Miller \& Hassanein, 1973) as a measure of the relative amount of soft tissue for length they are observed to carry above average amounts. That much of this is due to an excessive amount of body fat can be inferred from studies which have shown that the amount of subcutaneous fat, (itself directly related to total body fat) as measured by skinfold thickness, increases with birth weight (Oakley et al. 1977).

Reasons for excessive size at birth are poorly understood. In some instances it is caused by pathology in the foetus (e.g. Beckwith's Syndrome) or the mother (diabetes). However, according to Ounsted and Taylor (1971) biological factors play the most prominent part with mothers of HFD babies constituting a distinctive group compared with those who have either normal or LFD babies. They are older, of greater parity, taller, heavier, and have a low rate of previous spontaneous abortion. To explain these associations Ounsted \& Taylor (197I) 
speculate that these women somehow relax constraint on foetal growth rate to allow other (and as yet unidentified) biological factors to take up much of the variance of foetal growth. However, it is by no means clear (to this author at least) what this actually means. Since it is unusual for HFD babies to continue very heavy after birth, might it be that at some stage in the intra-uterine phase of development their mothers have somehow allowed them to fulfil a potential for rapid growth? Might it even be that intra-uterine growth rate can actually be enhanced by conditions in the mother?

$L F D$ babies. These are almost the mirror image of HFD babies. As a group they are much shorter than average and their heads are also smaller (Fig. I). The lower Ponderal Index points to them being leaner, due in major part to less body fat as indicated by diminished skinfolds (Usher, 1970 ). It is also likely that they have less muscle bulk (Widdowson et al. 1972).

A very small proportion of LFD babies have associated congenital abnormalities. In these, smallness can be considered an additional congenital anomaly. Smoking in the mother also contributes (Ounsted \& Taylor, 1971). However, most LFD babies fall into one of the two clinical categories. First, where smallness is due to genetic factors in the baby, representing the opposite end of a continuum of normal intra-uterine growth. These babies are often described as 'perfect miniatures'. Second, and these constitute the majority, where underweight is due to foetal undernutrition. These babies show to a varying extent the classic signs of wasting. In approximately one-half of these mothers there is a history of hypertensive disease during pregnancy (D. P. Davies, unpublished results). The remaining mothers are healthy and in these pregnancies it is possible that the placenta is somehow failing to function normally, maybe because of it having implanted in a poorly vascularized part of the uterus.

From this discussion it is evident that birth concludes a period of development when the foetus is remarkably sensitive to maternal genetic and environmental influences. Indeed, Polani (1974) has suggested that these factors account for about $80 \%$ of birth weight variation. After birth the baby's own mechanisms will have to steer growth into its true genetic channel.

\section{Growth over the first year}

Weight. In the first 6 months the mean distance curves of both HFD and LFD babies show marked shifts towards the mean (Fig. 2). Over the next 6 months the channel in which each weight curve continues is remarkably constant. The upward shift for LFD babies indicates above average weight gain, usually referred to as 'catch-up' growth. The downward shift in HFD babies indicates slower than average weight gain, or 'lag down'.

Length. As with weight, HFD babies show a distinct downward shift while those who are LFD again demonstrate upward shift (Fig. 3). However, the patterns are more complex than weight. HFD babies show most rapid downward shift in the first 3 months after birth with little further movement over the next 9 months. In the LFD infants upward shift takes place more gradually over the first 


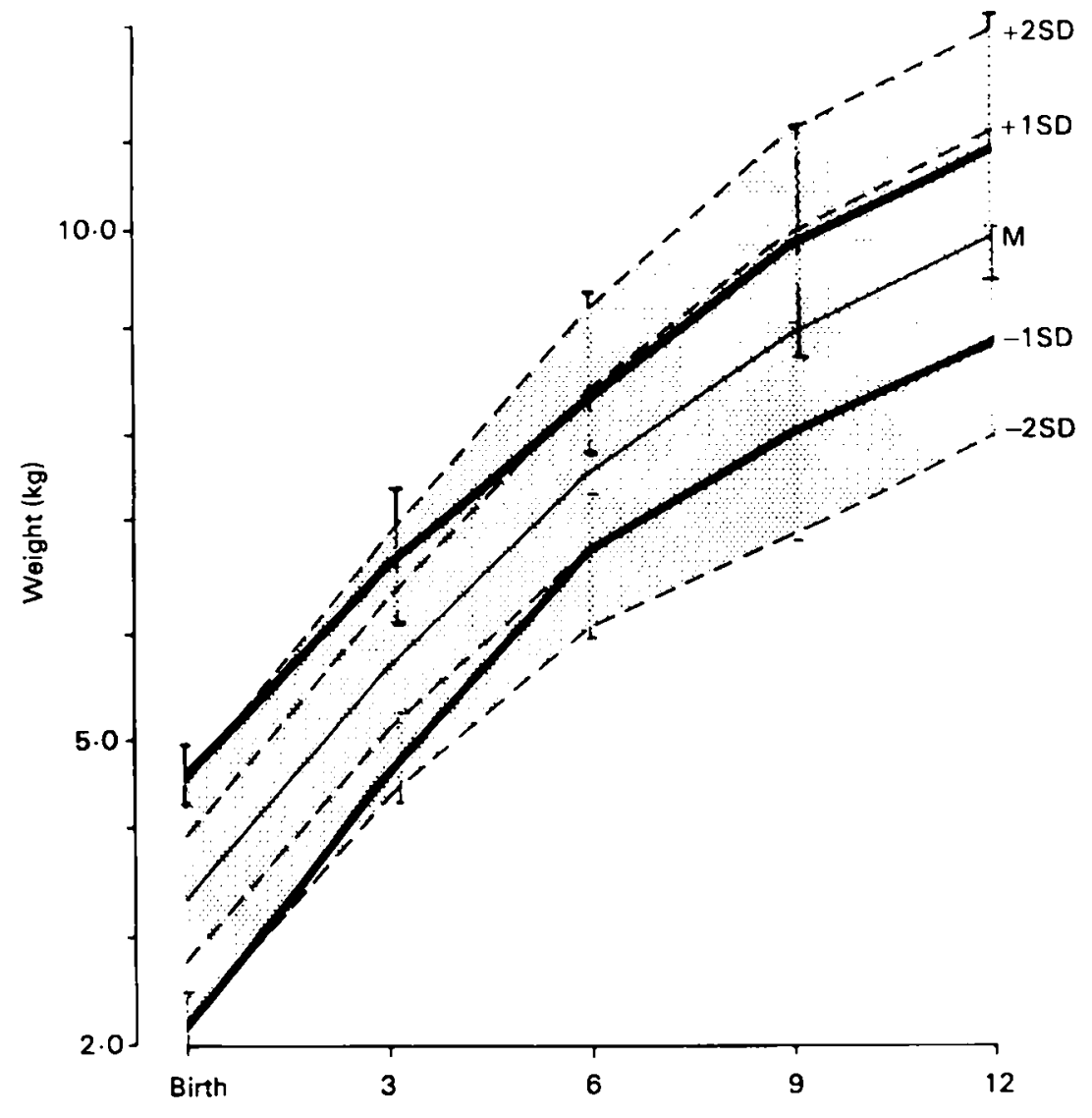

Age (months)

Fig. 2. Curves of mean weight gain ( $\pm I S D)$ over the first year of heavy-for-dates $\left(n 3^{8)}\right.$ and light-for-dates $(n+7)$ babies. The standard curves of comparison have been constructed from the results of Tanner (1978).

9 months. It is interesting that the extent of this upward shift is only about onehalf of the downward shift shown by the HFD babies. This implies that influences that constrain intra-uterine growth are less than those which provide for growth acceleration.

Head circumference. In contrast with weight and length, head circumference growth in the HFD babies shows little downward shift over the first year (Fig. 4). In contrast the LFD babies show a marked upward shift in the first 3 months with a more gradual continuation of this trend over the next 3 months. These observations suggest that the size of the head at birth in HFD babies, and therefore by inference that of the brain (Cooke et al. 1977), is more indicative of its genetic size than either its weight or length, i.e. it is least sensitive to maternal influences. In contrast the pronounced upward shift of head growth shown by the LFD babies indicates that the growth of the brain is considerably hindered by 


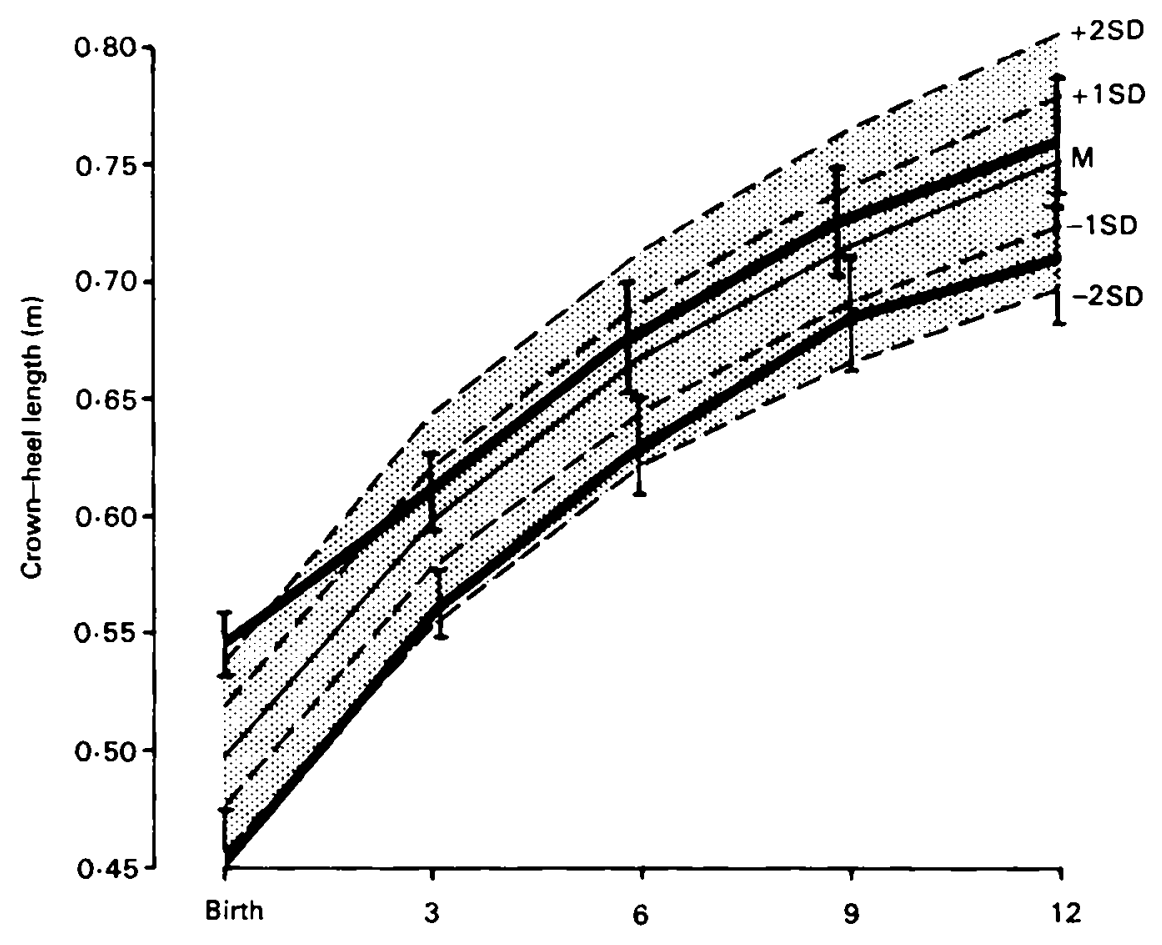

Age (months)

Fig. 3. Curves of mean length growth ( \pm I SD) over the first year of heavy-for-dates $\left(n 3^{8}\right)$ and light-for-dates $\left(n 5_{1}\right)$ babies. The standard curves of comparison have been constructed from the results of Tanner (1978).

intra-uterine constraining influences. The concept of brain spacing (Gruenwald, 1963) perhaps needs to be re-evaluated.

Skinfold thickness. Whitelaw (1977) studied skinfold thickness at birth and I year in several groups of babies. Of particular relevance to this paper are those babies categorized as obese (skinfolds $>90 \%$ centile) normal and thin (skinfolds $<10 \%$ centile). There were no significant correlations between skinfolds at birth and at I year. There were also no significant differences between the groups at I year. These findings indicate that HFD babies accumulate subcutaneous fat at a slower rate than do LFD babies.

Changes in 'fatness' and 'leanness'. Fig. 5 shows changes in the Ponderal Index over the first year in HFD, LFD and appropriate for dates (AFD) babies. At birth the HFD babies had a significantly higher Ponderal Index than AFD babies indicating relative fatness, while LFD babies a significantly lower Ponderal Index indicating wasting. However, at I year the Ponderal Index in each of the three groups was the same. With the Ponderal Index being directly related to skinfold thickness (Raemakers, 1977), these findings indicate that HFD babies become leaner and LFD babies fatter over the first year. 


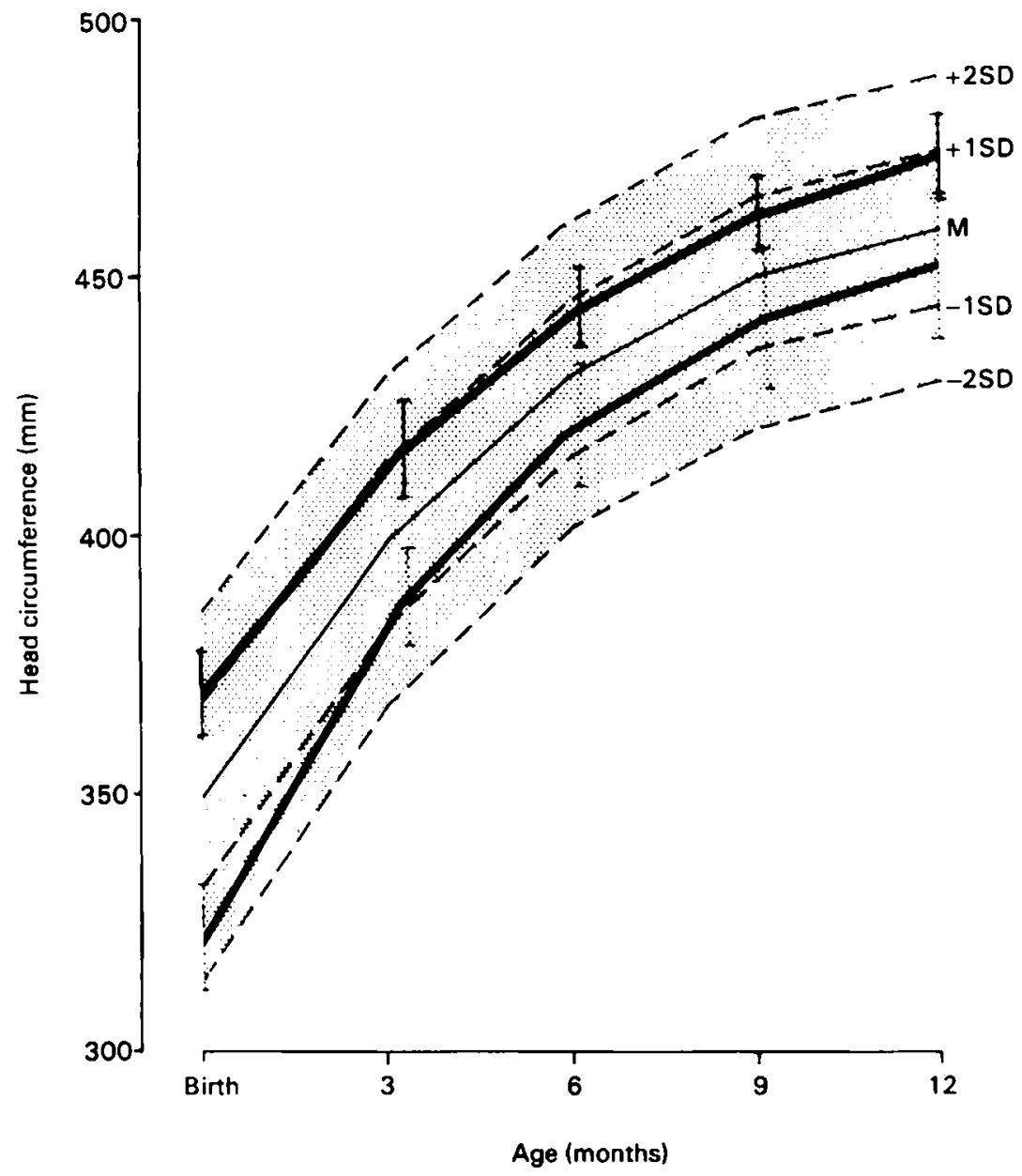

Fig. 4. Curves of mean head circumference growth ( \pm I SD) over the first year of heavy-for-dates $\left(n 3^{8}\right)$ and light-for-dates $\left(n n_{1}\right)$ babies. The standard curves of comparison have been constructed from the results of Tanner ( 1978$)$.

Over the first year it would therefore appear that compared with their size at birth HFD babies as a group grow to become relatively shorter, lighter and less fat while LFD babies become relatively heavier, longer, fatter and bigger headed. These conclusions complement those of Ounsted and Taylor (1971) derived from cross sectional studies. Birth therefore removes babies of extreme size from powerful maternal influences which have played such an important part in causing such extremes of foetal growth rate. The babies' own regulatory mechanisms, about which very little is known other than they are mediated in some way through genetic forces which in turn are related to parental size, are allowed to draw the trajectories of growth back into the normal size range. This process seems to take place mainly over the first six months. The sensitivity of the various growth regulators is, however, unequal at the two extremes of foetal growth 


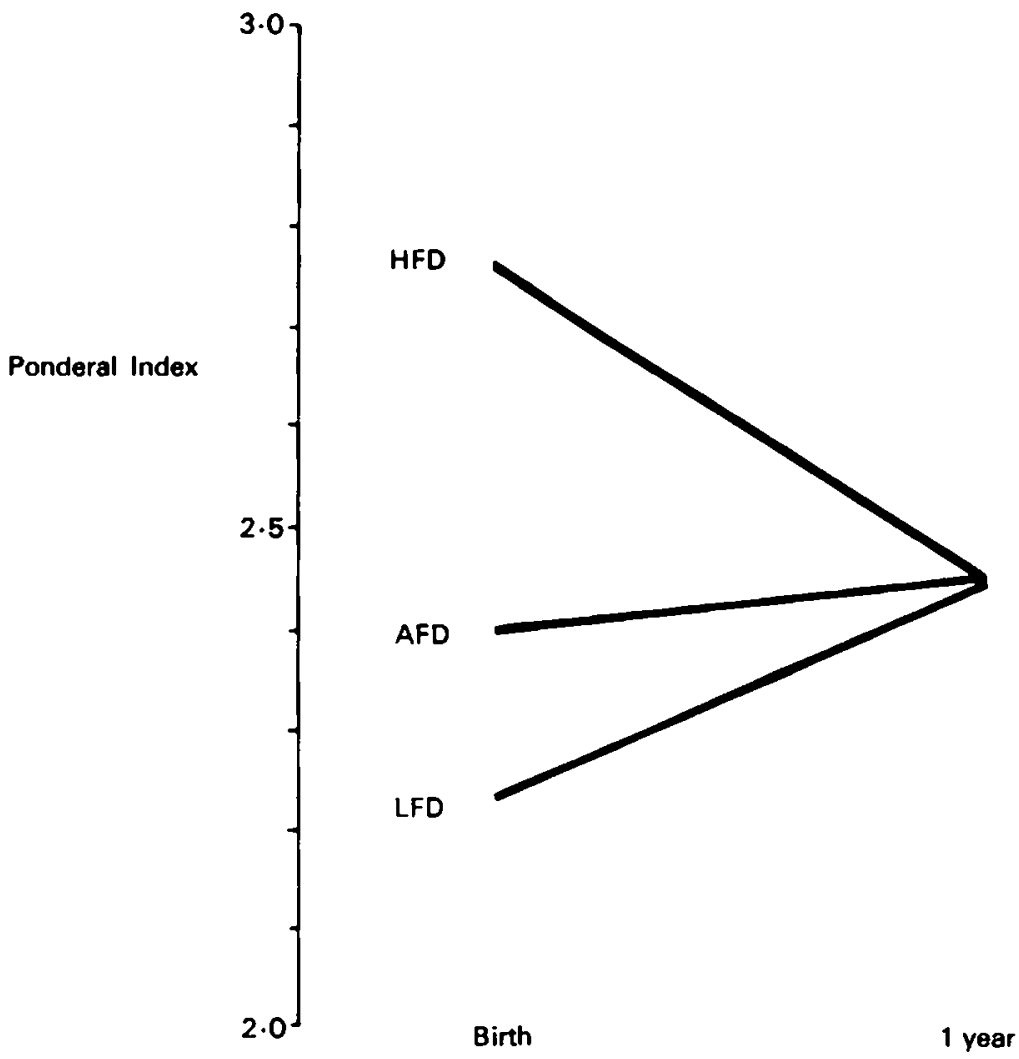

Fig. 5. Changes over the first year in the mean Ponderal Index of heavy-for-dates $\left(n 3^{8}\right)$; appropriate-for-dates ( $n$ I00) and light-for-dates $(n+7)$ babies.

(Table I). Thus, while weight in HFD babies 'hurries towards the mean' slightly quicker than it does in LFD babies, the movement for length is more than twice that of the LFD babies. The extent of shift for head circumference in the LFD babies is four times that for HFD babies.

It is interesting that growth regulation is also concerned with control of body shape. Thus, while at I year there are still marked differences in size between

Table 1. Shifting growth between birth and one year

(Expressed as the differences between the mean standard deviation scores at the two ages)

$\begin{array}{cccc}\text { Infant category } & \text { Weight } & \text { Length } & \begin{array}{c}\text { Head } \\ \text { circumference }\end{array} \\ \text { 'Heavy-for-dates' } & -1.40 & -2.20 & -0.28 \\ \begin{array}{c}\left(n 3^{8}\right) \\ \text { 'Light-for-dates' } \\ (n 47)\end{array} & +1.00 & +1.03 & +1.07\end{array}$


HFD, LFD and AFD babies, their body proportions in terms of weight for length are the same. This is particularly intriguing in the light of Dr Margaret Ounsted's hypothesis (Ounsted, 1977) that a certain proportionality is required for a baby to be able to sit, stand and walk at the appropriate time.

\section{Variations in growth patterns}

While the previous findings indicate that for infants at both extremes of size at birth the over-all pattern of growth is one of 'hurrying towards the mean', very diverse patterns are seen when individual growth curves are examined (Fig. 6). For example, of thirty-eight HFD babies only eight $(2 \mathrm{I} \%)$ saw their weight continue in the same channel in which they were born, i.e. their intra-uterine pattern was sustained after birth. Two (5\%) showed an upward shift to become relatively even heavier. However, most $(28-74 \%)$ showed downward shifts to varying degrees. Of fifty-four LFD babies seventeen $(32 \%)$ continued in the same channel as at birth. Thirty-four $(64 \%)$ showed upward shift and three $(4 \%)$ had an indeterminate pattern. No LFD baby showed downward shift. Similar diverse

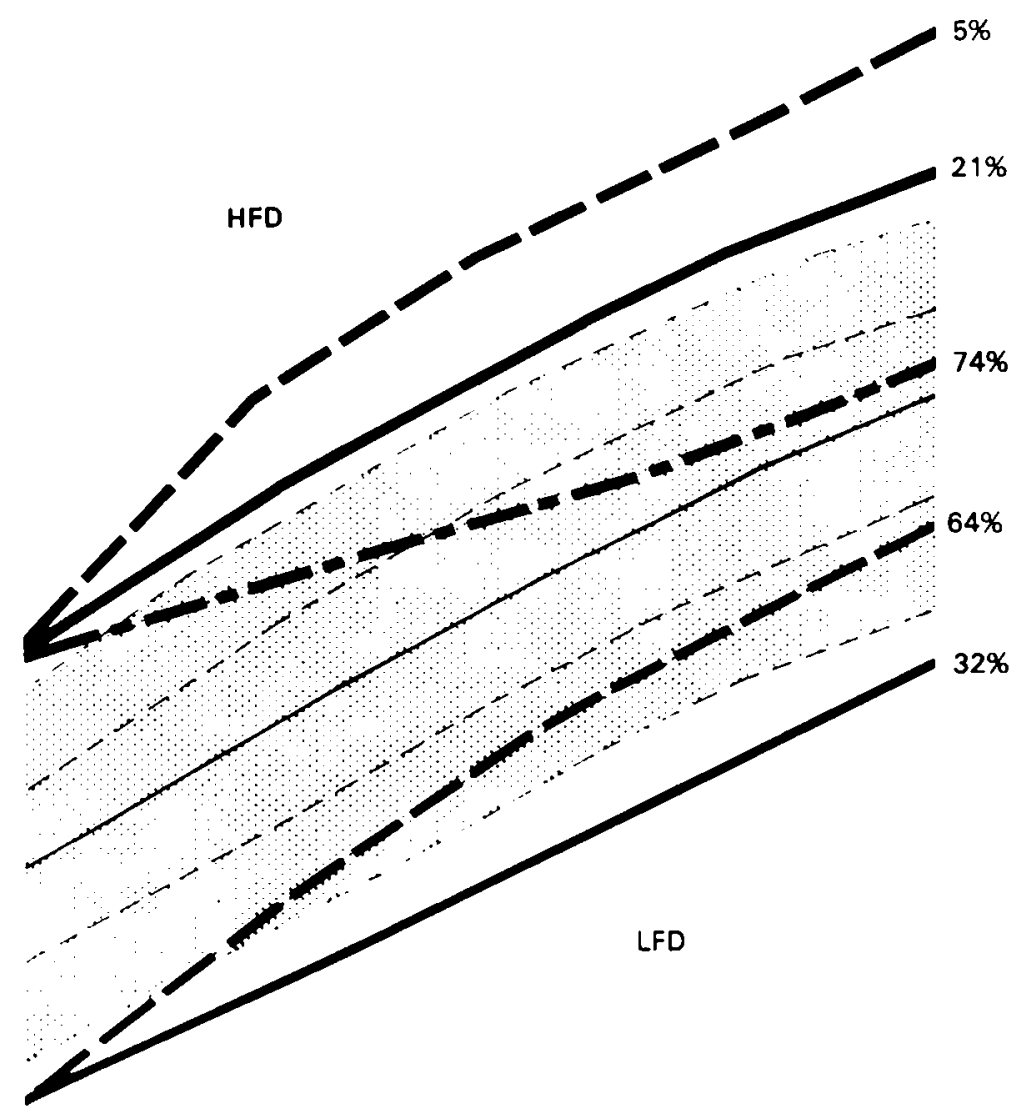

Fig. 6. Diversity in the patterns of weight curves over the first year in heavy-for-dates $(n 38)$ and light-for-dates $(n+7)$ babies. Two of the light-for-dates babies have not been included because of an indeterminate pattern of weight gain. 
patterns were also noted for length and head circumference, the latter mainly in the LFD babies.

This remarkable diversity of growth patterns within both HFD and LFD groups must undoubtedly reflect the extent in an individual baby to which intra-uterine environmental influences and its own genetic machinery for growth control interact. Careful study of postnatal growth might therefore go some way in helping to understand the cause of abnormal intra-uterine growth.

\section{Conclusion}

Other than for its obvious biological interest, doctors, nurses and other health workers need to understand patterns of longitudinal weight gain in HFD and LFD babies during infancy if they are to reliably assess health and nutritional wellbeing. In the light of the present investigation the following points might be helpful.

LFD babies. If weight remains in the same channel (or rarely reaches an even higher centile), there should be no need for further investigation. Babies showing such patterns are likely to be genetically big babies. If there is downward centile crossing this should not be cause for worry, provided of course that these babies are indeed showing a 'physiological' lag down and not failing to thrive. In most cases the problem can be resolved by careful clinical history and examination.

HFD babies. If these are seen regularly after birth most will show centile crossing in an upward direction: this is normal. If the curve of weight gain continues in the same centile channel these babies are most likely to be genetically small, although if they continue to show signs of wasting they may be failing to show 'catch up' in which case investigation will be needed. If there is a fall off in weight gain there is a definite need for further investigation.

\section{REFERENCES}

Cooke, R. W. I., Lucas, A., Yudkin, P. H. N. \& Pryse-Davies, J. (1977). Early hum. Dev. 1, 145.

Fomon, S. J. (1974). Infant nutrition. 2nd ed. p. 34. Philadelphia. London. Toronto: W. B. Saunders Company.

Gruenwald, P. (1963). Biology Neonate 5, 2 r5.

Miller, H. C. \& Hassanein, K. (1973). Pediatrics 52, 504.

Oakley, J. R., Parsons, R. J. \& Whitelaw, A. G. H. (1977). Archs Dis. Childh. 52, 287.

Ounsted, M. (1977). Am. F. Dis. Child. I31, 1076.

Ounsted, M. \& Ounsted, C. (1973). Clinics in Developmental Medicine. No. 46 p. I 17 . Spastics International Medical Publications. William Heinemann Medical.

Ounsted, M. \& Taylor, M. G. (1971). Cerebr. Palsy Bull. 13, 421.

Polani, P. (1974). Size at Birth p. 127. Ciba Symposium 27 (new series). Amsterdam, Oxford, New York: Elseview. Excerpta Medica. North Holland. Associated Scientific Publishers.

Raemakers, L. H. J. (1977). Br. Neonatal Soc. Abstr. (Oxford), June, p. 23.

Rohrer, F. (1921). Münch. Med. Wschr. 68, 580.

Tanner, J. M. (1978). In Textbook of Paediatrics. 2nd ed. p. 249. Edinburgh, London, New York: Churchill Livingstone.

Tanner, J. M. \& Thompson, A. M. (1970). Archs Dis. Childh. 45, 566, 73-84.

Usher, R. H. (1970). Pediat. Clins. N. Am. 17, 169.

Whitelaw, A. (1977). Lancet ii, 1098.

Widdowson, E. M., Crabb, D. E. \& Milner, R. D. G. (1972). Archs Dis. Childh. 47, 652. 